SLOVO, sv. 71 (2021), 169-188, Zagreb 2020.

Sanja ZUBČIĆ

Filozofski fakultet Sveučillišta u Rijeci

UDK 811.163.42'367.625

272-282.7:003.349.1

sanja.zubcic@uniri.hr

Izvorni znanstveni članak

Primljen: 16. lipnja 2020.

Prihvaćen: 20. listopada 2020.

\title{
JEDNOSTAVNI GLAGOLSKI OBLICI U TEMPORALU DRUGOGA BERAMSKOGA BREVIJARA
}

U radu se analizira morfologija jednostavnih glagolskih oblika u temporalu Drugoga beramskoga brevijara: prezenta, sintetskoga imperativa, imperfekta i aorista. Podatci se uspoređuju sa stanjem opisanim u liturgijskim tekstovima pisanim hrvatskim crkvenoslavenskim jezikom. Pozornost se posvećuje i onim značajkama koje predstavljaju odstupanja od norme hrvatskoga crkvenoslavenskoga jezika i koje su u tekstove ušle iz govorne čakavštine. Radom će se pridonijeti cjelovitijem poznavanju morfologije jednostavnih glagolskih oblika u hrvatskom crkvenoslavenskom jeziku, a ekscerpirani će govorni, čakavski elementi moći poslužiti pri utvrđivanju tempa promjena u hrvatskom jeziku.

Ključne riječi: Drugi beramski brevijar, temporal, prezent, sintetski imperativ, imperfekt, aorist

\section{UVOD}

Istraživanje morfoloških značajki glagola, osobito njegovih jednostavnih glagolskih oblika, poticajno je stoga što se u tom jezičnom segmentu isprepliću značajke norme hrvatskoga crkvenoslavenskoga jezika i elementi govornoga, čakavskoga jezika. ${ }^{1}$ Poznato je da taj odnos i stupanj infiltracije čakavskih

1 U morfologiji složenih glagolskih oblika elementi koji mogu upućivati na utjecaj govornoga jezika svode se na promjene jednostavnih glagolskih oblika koji kao pomoćni glagoli sudjeluju u njihovoj tvorbi, najčešće prezenta (budem' rekli i budemo rekli). Djelomično se izdvaja kondicional u čijoj se tvorbi, još od starocrkvenoslavenskoga jezika, potvrđuju optativni oblici glagola biti koji i danas postoje u čakavskim, osobito u sjevernočakavskim govorima. Prema HCSJ (2014: 259) u hrvatskom crkvenoslavenskom jeziku u 1. licu jd. prevladavaju 
elemenata ovisi o tipu teksta te da će on biti to veći što je tekst svjetovnijega sadržaja, tj. manjih stilskih zahtjeva (DAMJANOVIĆ 2008: 7-23). Stoga je u liturgijskim tekstovima slabija infiltracija čakavskih elemenata no što je to u svjetovnim tekstovima različitoga tipa, ali je redom potvrđivana. Analizom tih značajki i njihovim krozvremenskim praćenjem u većem broju tekstova, omogućeno je utvrđivanje tipa promjena koje su se provodile u organskim idiomima te njihov tempo, a to je važno za precizniju dataciju promjena u razvoju hrvatskoga jezika. ${ }^{2}$ Više na teorijskoj no na praktičnoj razini, iz tih bi se govornih elemenata dalje mogle iščitavati značajke govora pojedinoga pisca pa kroz njih i značajke konkretnoga govora kojim pisac govori čime bi analiza imala smisla i u povijesnoj dijalektologiji. ${ }^{3}$

Korpus za ovo istraživanje prvi je dio dvosveščanoga Drugoga beramskoga (ljubljanskoga) brevijara koji sadrži temporal i sastoji se od 264 folije. ${ }^{4}$ O rukopisu Drugoga beramskoga brevijara (dalje BrBer $_{2}$ ) i njegovu jeziku

oblici s bimb, a u 1. licu mn. s bihomb, a tako je i u temporalu $\operatorname{BrBer}_{2}(37$ je potvrda za bimb, 5 za bihs i 12 za bêhb / bêh').

2 U dataciji jezičnih promjena u organskim idiomima problem predstavlja vrlo ograničen korpus kojim bi se teze mogle argumentirati. Pravnih je tekstova koji su pisani jezikom najbližim govornom relativno malo i sve manje što se ide dublje $u$ jezičnu povijest. Govorne su pak značajke u neliturgijskim i osobito u liturgijskim tekstovima (svjesno ili nesvjesno) izbjegavane u nastojanju da se poštuje norma hrvatskoga crkvenoslavenskoga jezika. Iako malobrojne, uz onomastičku građu, nerijetko su jedini izvor za rekonstrukciju starijih jezičnih stanja u organskim idiomima.

3 Pri konkretizaciji takova nastojanja mnogo je zapreka. Najveća proizlazi iz činjenice da se u komunikaciji (pisanoj ili govornoj) s pripadnicima druge govorne skupine najprije eliminiraju one jezične značajke koje su determinirajuće i koje tu skupinu govornika razlikuju od neke druge (JUTRONIĆ 2010; VRANIĆ; ZUBČIĆ 2015), a upravo su te razlikovne značajke u dijalektologiji važne jer se na temelju njih utvrđuje pripadnost nekom konkretnom mjesnom govoru. Značajke većega stupnja apstraktnosti, tj. one koje se potvrđuju u većem broju govora, nemaju taj stupanj razlikovnosti i na temelju njih nije moguće utvrditi pripadnost konkretnom mjesnom govoru već nekoj višoj, apstraktnijoj dijalekatskoj realnosti poput, primjerice poddijalekta i dijalekta. S. Vranić (2020) sustavno je istražila čakavske elemente u temporalu $\mathrm{BrBer}_{2}$ i dokazala kao se najčešće radi o »općečakavskim« elementima. Od elemenata koji bi mogli upućivati na utjecaj beramskoga govora, ističe $o$-refleks stražnjega nazala koji se potvrđuje u nekoliko primjera te povećan broj ekavizama.

4 Drugi beramski brevijar hrvatskoglagoljski je rukopisni kodeks iz 15. stoljeća koji se čuva u Narodnoj i sveučilišnoj knjižnici u Ljubljani (signatura Ms 163) zbog čega je u literaturi poznat i kao Drugi ljubljanski brevijar. Sastoji se od dva dijela: prvi je dio temporal (Proprium de tempore, sadrži molitve i čitanja kroz godinu), a drugi sanktoral (Proprium sanctorum, sadrži molitve i čitanja za svetačke blagdane). 2018. godine objavljen je faksimil i transliteracija njegova prvoga dijela (BADURINA STIPČEVIĆ i dr. 2018), a 2019. drugoga (BADURINA STIPČEVIĆ i dr. 2019). 
pisao je opsežno Milan Mihaljević (2011). Prvu je vijest o njemu donio Josef Vajs (1910: XVI-XXV), a kasnije i Ivan Milčetić (1911: 65-69). Nakon osnutka Znanstvenoga centra izvrsnosti za hrvatsko glagoljaštvo kojemu je temeljni cilj objava faksimila obaju dijelova Drugoga beramskoga brevijara te temeljita jezična, kodikološka, paleografska, teološka i povijesnoumjetnička analiza napisano je o tom rukopisu više članaka. ${ }^{5}$ Istraživanje morfologije glagola Drugoga beramskoga brevijara započeo je Milan Mihaljević (2011: 133-134), Sanja Zubčić u dvama se svojim radovima $(2015,2016)$ posvetila morfonološkim alternacijama u osnovama glagola, a imperativom, u dijakronijskom smislu, Ana Šimić i Jozo Vela (2018). Jezikom hrvatskoglagoljskih tiskanih brevijara bavio se Ivan Jurčević, a osim monografije (2002), napisao je, u suautorstvu s Ružicom Tolić raspravu o glagolskim oblicima u sanktoralu prvotiska brevijara (2011). Temeljitije su istraženi glagoli u misalima. Josip Galić objavio je studiju o jednostavnim (2014) i složenim (2016a) glagolskim oblicima u Hrvojevu misalu, te usporedbu oblika u Hrvojevu misalu i Hvalovu zborniku (2016b), a Blanka Ceković, Ivana Sanković i Mateo Žagar (2010) te Blanka Ceković i Ivana Eterović (2012) pisali su o različitim aspektima glagola u Kožičićevu misalu. Glagolima u lekcionaru bavila se Ksenija Režić (1980), u fragmentima Milan Mihaljević (2008), a u djelima hrvatskih protestanata Tanja Kuštović (2017). Podatci o morfologiji glagola u hrvatskom crkvenoslavenskom jeziku sastavni su dio monografija posvećenih nekom određenom tekstu, poput Milana Mihaljevića i Jasne Vince (2012), Marinke Šimić (2014), Milana Mihaljevića (2018) i dr., ali i gotovo svih radova posvećenih određenim rukopisima kao i u sintetskim raspravama poput Reinhartove (1988). Za ovu su temu najvažnija dva teksta: knjiga Sofije Gadžijeve (2012) o alternacijama u prezentskim osnovama glagola te studija o morfologiji glagola u hrvatskom crkvenoslavenskom jeziku, iz pera Sofije Gadžijeve i Milana Mihaljevića (2014: 205-260). One su, a osobito potonja, važan izvor pri komparativnoj analizi podataka iz liturgijskih tekstova (jer takvi čine najveći dio korpusa). Slabije je istražena morfologija glagola u neliturgijskim glagoljskim zbornicima. Eduard Hercigonja napisao je disertaciju o jeziku Petrisova zbornika (1968) te rad o dvojini u zborničkoj literaturi (1999), a Stjepan Damjanović intenzivno se bavio jezikom Kolunićeva zbornika (1982).

5 Iako pravila akademskoga diskursa ne dopuštaju ovakvu podatcima neargumentiranu tezu, ipak ću posegnuti za njom i to iz razloga što je tih studija mnogo, a budući da svaka obrađuje svoj segment koji u ovom radu nije ključan, njihovo bi navođenje nepotrebno opteretilo rad. 
Cilj je ovoga rada analizirati morfološke značajke jednostavnih glagolskih oblika: ${ }^{6}$ prezenta, sintetskoga imperativa, aorista i imperfekta u temporalu Drugoga beramskoga brevijara. ${ }^{7}$ Iako se u jednostavne glagolske oblike nerijetko ubrajaju i participi (usp. npr. HCSJ 2014: 211-250; GALIĆ 2014 i dr.), ovdje će se oni izostaviti. ${ }^{8}$ Dobiveni će se rezultati postaviti u kontekst jezika liturgijskih djela pisanih hrvatskim crkvenoslavenskim jezikom, s time da će se podatci o normi toga jezika uzimati iz gramatike hrvatskoga crkvenoslavenskoga jezika (HCSJ 2014). Posebna će se pozornost posvetiti oblicima koji odstupaju od hrvatskocrkvenoslavenske norme. Oni će se usporediti sa sličnih odstupanjima u ostalim liturgijskim hrvatskoglagoljskim tekstovima te sa stanjem u čakavskom koji čini narodnu komponentu u tekstovima. Korpus za ovo istraživanje preuzet je iz računalne baze podataka koja se priprema u Znanstvenom centru izvrsnosti za hrvatsko glagoljaštvo (https://beram.stin. $\mathrm{hr} / \mathrm{hr} /$ transliteration/53/1), uz ekscerpirane se primjere navode, redom, broj folije, slovna oznaka stupca i redak.

Budući da u korpus tekstova analiziranih za sastavljanje gramatike hrvatskoga crkvenoslavenskoga jezika (HCSJ 2014) nije ušao Drugi beramski brevijar, ovaj će rad doprinijeti i sveukupnoj istraženosti hrvatskoga crkvenoslavenskoga jezika, a usto će produbiti spoznaje o morfologiji glagola u tom jeziku te o tipovima promjena u tom segmentu.

S obzirom na vrstu analiziranoga teksta (liturgijski) te na vrijeme njegova nastanka (15. stoljeće) pretpostavlja se da će se stanje najvećma podudarati sa stanjem u ostalim liturgijskim hrvatskoglagoljskim tekstovima. Prema jezičnotekstološkim značajkama oni se dalje dijele sjeverne ili krčko-istarske i južne ili zadarsko-krbavske. Vesna Badurina-Stipčević, Milan Mihaljević i Marinka Šimić ističu da »bi preciznije bilo govoriti o starijoj i mlađoj redakciji nego o sjevernoj i južnoj, jer neki tekstovi nastali u Istri pripadaju

${ }^{6}$ U hrvatskoglagoljskim tekstovima potvrđen je i supin (HCSJ 2014: 230), no u temporalu BrBer $_{2}$ nije potvrđen. Nema ga u Kožičićevu i Hrvojevu misalu, dok je u Illirico 4 i u Ročkom misalu rijedak (GALIĆ 2014: 86).

7 Glagolski oblici izložit će se ovim redom, prema tipu osnova od kojih se tvore.

8 Louis Hjelmslev u Principes de grammaire générale (1929) ističe da participe nije opravdano vezati uz sustav glagolskih oblika (prema HERCIGONJA 1999: 133). S obzirom na gramatičke kategorije i pripadajuće promjene u tom segmentu koje su pratile promjene imenskih vrsta riječi, na sintaktičke značajke, ali i na akcenatske značajke (glagolski pridjevi koji su se razvili iz participa ulaze u čakavskim govorima u akcenatske tipove pridjeva, usp. ZUBČIĆ 2003; VRANIĆ 2011: 125-131), smatram da je morfološke značajke participa uputnije analizirati u morfologiji pridjeva i priloga. Ono što je u njima nedvojbeno »glagolski« segment, pitanje je osnova i temeljno značenje. 
među najreprezentativnije predstavnike mlađe (južne skupine)« (BADURINA-STIPČEVIĆ; MIHALJEVIĆ; ŠIMIĆ 2012: 262). O pripadnosti BrBer jednoj od dviju skupina liturgijskih knjiga spomenuti autori tvrde da prema jezičnotekstološkim osobinama on ulazi u tzv. južnu ili mlađu skupinu hrvatskoglagoljskih brevijara, dok prema Silvani Vranić »dosadašnji pokušaji utvrđivanja vernakularnih činjenica na određenom broju folija s aspekta dijakronijske dijalektologije pokazuju da taj dio temporala pripada sjevernomu, krčko-istarskomu, tipu liturgijskih tekstova. Razlog je takvomu zaključku u prvom redu pretežitost $\check{z} d$-refleksa jotacije dentala $d \ll$ (VRANIĆ 2020: 267).

\section{PREZENT}

\subsection{Tematski glagoli}

U morfologiji prezenta u hrvatskom crkvenoslavenskom jeziku jedina je razlika u odnosu na starocrkvenoslavenski jezik u poopćavanju nastavka -ta na 3. lice dvojine, s time da je pojava sporadično potvrđena i u nekim kanonskim tekstovima (HCSJ 2014: 214).

$\mathrm{U}$ temporalu $\mathrm{BrBer}_{2} \mathrm{u}$ 1. licu jd. apsolutno pretežu oblici s nastavkom $-u$ :

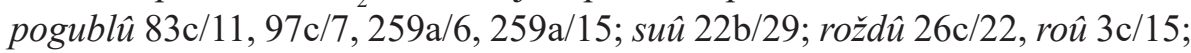
v'ziçu 74b/28; v'zveliču 98b/3, 99c/17; роси 218a/23; krĉu 21b/4 i dr. Vrlo je rijetko, manje od deset puta, potvrđen i nastavak - $m$, preuzet iz atematskih glagola: obedimb 95c/4; vraĉaem' 183b/32; sveĉam' 172c/10; upvamb 243d/26; počnems $240 \mathrm{c} / 12$; gremb $181 \mathrm{c} / 27$. Kadšto se u istoj rečenici potvrđuju oblici s nastavkom -u i nastavkom -m: êko s(vê)ta $n(e) b(e) s e$ ne viû · na upvamь $v$ g(ospod) a êko ne ostavit me $243 \mathrm{~d} / 26$. Iz navedenih je primjera evidentno da su tendenciji podložniji glagoli s osnovom na $a$, a isto je već od 13. stoljeća u toj skupini glagola potvrđeno i u organskim idiomima (MATASOVIĆ 2009: 91). Prema istom autoru nastavak $-m$ potom se širi na $i$-glagole, a od 15 . stoljeća i na $e$-glagole. Pretežitost nastavka $-u$ karakterizira i ostale hrvatskoglagoljske liturgijske tekstove, a autori gramatike (HCSJ 2014: 214) bilježe rijetke iznimke, ali samo u glagola e-tipa: pred'idemb 59a iz Senjskoga misala; prizovem Ps 101,3 iz Prvotiska brevijara; zn'mb 59d iz Senjskoga misala te znamb 51d iz Prvoga oxfordskog misala.

U 2. licu jd. u temporalu BrBer $_{2}$ nije zabilježena potvrda nastavka $-\check{s} b$, kao ni u ostalom usporednom korpusu. Potvrđeni su oblici: miriši 256a/1; zaĉitiši 241a/11; otvrzaeši 56a/29, 111b/1, 145d/22; um'reši 38c/27; vzradueši 56d/2 i 
dr. Taj nastavak pretežit je i u ostalim hrvatskoglagoljskim liturgijskim tekstovima, a nastavak -šs / -̌̌ češći je u glagola $i$-tipa (HCSJ 2014: 215).

U 3. licu jd. prevladava nastavak -tb: vzdadetb 114a/32, 178b/1; gib 'let' $135 \mathrm{~b} / 28$; oskvrnit $256 \mathrm{~b} / 10$; otacit' $84 \mathrm{~d} / 16 \mathrm{i}$ dr. Oblici bez dočetnoga -t znatno su rjeđi, ima ih oko $3 \%,{ }^{9}$ a potvrđeni su najvećma u rubrikama: dae (komu $n(e) d(\hat{e}) l a$ mes'to dae 262b/29); govori (do oktabi petikostb ne govori se ot ap(usto)lb 1b/23), 5a/21, 6d/28,161a/24, 262d/6, 263b/4, 1b/23; grede (ot onogo blag'dane ki za nimb grede 262c/2); brže (ki se veliko brže v nikihb gradehb 262a/1). Rjeđe su izvan rubrike: bude 85a/2; hoce 228d/6; ispitue 234a/13; iz'bavlae 33b/14 i dr. Jednako je i u ostalim hrvatskoglagoljskim liturgijskim tekstovima. »Oblici bez završnoga - $t$ pojavljuju se već u 13. st., primjerice $d a$... m(o)li FgTs 1a, oběnčava FgTs 2d. I u kasnijim je hrvatskoglagoljskim liturgijskim tekstovima većina oblika s tim zamjenama potvrđena u rubrikama, dok su u službenom, liturgijskom (osobito biblijskom) tekstu iznimno rijetka pojava, npr. ne može $\mathrm{BrVb}_{2} 233 \mathrm{~b}$, věrovati se može MVat $_{4} 43$ b i sl.)« (HCSJ 2014: 213).

$\mathrm{S}$ obzirom na to da u tekstovima starije hrvatske književnosti i u organskim idiomima nema nikakva traga da je u prezentu 3. lica jd. i mn. bilo dočetno $-t$ (MATASOVIĆ 2008: 264, bilj. 349), zabilježene potvrde bez njega nedvojbeno su rezultat utjecaja govornoga jezika.

U 1 . licu mn. pretežit je nastavak $-m b /-m^{\prime} /-m$, ali je u oko $19 \%{ }^{10}$ pojavnica nastavak -mo koji je činjenica govornoga jezika: govorimo $4 \mathrm{~b} / 9,7 \mathrm{~b} / 8$; hinimo 138d/12; hodimo 104a/23, ali i hodimb; hoĉemo 49d/9, 104a/10, 214c/12, $229 \mathrm{c} / 2$, ali i hoĉemb $2 \mathrm{c} / 20$; icemo $124 \mathrm{a} / 21,189 \mathrm{c} / 9$, ali i icemb $70 \mathrm{a} / 27,119 \mathrm{~d} / 20$, 138a/10; ležimo 127a/20; mislimo 227a/9, ali i mislimb 66a/12 i dr. Za razliku od oblika 3. lica jd., tu nije primijećena povezanost s tipom teksta, odnosno oba su oblika jednoliko distribuirana. U ostalim tekstovima pisanim hrvatskim crkvenoslavenskim jezikom opservirano je da se nastavak -mo češće potvrđuje $u$ kodeksima koji i inače imaju više narodnih elemenata te u mlađim tekstovima, osobito u sanktoralu misala i u brevijarima, dok se u starijim tekstovima i u onima koji čuvaju starije prijevode s grčkoga češće potvrđuje -mb (HCSJ 2014: 213).

9 Kvantitativni se podatci izvode iz računalne baze podataka beram.stin. $h r$ koja se priprema u Znanstvenom centru izvrsnosti za hrvatsko glagoljaštvo. Ta je baza još uvijek neprovjerena $i$ u konačnici bi moglo doći do manjih promjena koje ni na koji način ne bi mijenjale cjelokupnu sliku.

${ }^{10}$ Od ukupno 396 pojavnica prezenta 1. lica mn. u 75 njih potvrđen je nastavak -mo. 
U 2. licu mn. očekivano nema nikakvih zamjena dok u 3. licu mn., jednako kao u 3. licu jd. pretežu oblici s dočetnim -tb. Kvantitativnom je analizom utvrđeno da samo $4 \%{ }^{11}$ od ukupnoga broja pojavnica dolazi bez dočetnoga -tb: brgu 262c/16, 262d/17, 262d/25; dêu 167b/24; v'nidu 233b/13, ali češće v'nidutb $139 \mathrm{a} / 14,139 \mathrm{a} / 22,139 \mathrm{a} / 23$; postave $14 \mathrm{~b} / 14$, ali i pos'tavetb $130 \mathrm{~b} / 10$; čine $263 \mathrm{a} / 29,263 \mathrm{~d} / 10 \mathrm{i} \mathrm{dr}$.

Potvrđena je dvojina kao kategorija. U 1. licu dv. su nastavci -vê i -ve: ozlobivê $9 \mathrm{~d} / 18$; postavivê $9 \mathrm{~d} / 20$; vitrg'nevê $9 \mathrm{~d} / 19$; spriem 'lêve $154 \mathrm{c} / 13$; tvorive $242 \mathrm{~b} / 17,243 \mathrm{~d} / 6$, a samo u jednom primjeru i ideva $89 \mathrm{~d} / 14$. Nastavak -va posvjedočen je u tekstovima hrvatskoglagoljske neliturgijske književnosti 15. stoljeća (HERCIGONJA 1999: 135; DAMJANOVIĆ 2008: 127-128), a potvrđen je i u Hrvojevu misalu pa se smatra utjecajem onodobnih književnih tekstova (GALIĆ 2014: 143). Nedvojbeno je riječ o tendenciji paradigmatskoga ujednačavanja prema nastavcima 2. i 3. lica dv. koje je najprije provedeno u stilistički manje zahtjevnim, neliturgijskim tekstovima, iz kojih se pak proširio i u liturgijske. Budući da je proces gubljenja dvojine dugotrajan proces koji je definitivno okončan u 16. stoljeću (LUKEŽIĆ 2015: 22), moguće je pretpostaviti da do istoga paradigmatskoga ujednačavanja dolazi i u organskim idiomima odakle se preuzima u pisane tekstove. U 2. i 3. licu dv. sustavan je nastavak -ta: 2. lice: boita $37 \mathrm{c} / 23$, obrêceta $141 \mathrm{a} / 28$, otvrzeta 92c/33; 3. lice: hvalita $127 \mathrm{~d} / 14$, is pravlaeta $142 \mathrm{a} / 18 \mathrm{i}$ dr. Isto je potvrđeno i u ostalim liturgijskim hrvatskoglagoljskim tekstovima (HCSJ 2014: 213).

Zaključno, u prezentu tematskih glagola $u$ analiziranom se tekstu potvrđuje čvrstoća norme hrvatskoga crkvenoslavenskoga jezika. Odstupanja su sporadično potvrđena u 1. licu jd., te 3. licu jd. i mn. Najbrojnija je inovacija nastavak -mo u 1. licu mn. za koju se smatra da je u govornom jeziku započela koncem 11. stoljeća (LUKEŽIĆ 2015: 306) pa je do 15. stoljeća već bila potpuno provedena i postala je dio uzusa, zasigurno bez varijantnosti. Ta stabilnost nastavka -mo u govornom uzusu razlog je njegovoj sve snažnijoj penetrativnosti i u jezik liturgijskih knjiga.

\subsection{Atematski glagoli}

Pet je atematskih glagola koji vrlo često dolaze prefigirani pa čine velik broj različitih leksema s istom osnovom. Neovisno o prefiksu, oni pokazuju

\footnotetext{
${ }^{11}$ Potvrđene su ukupno 794 pojavnice, a 35 njih dolazi bez dočetnoga -tb.
} 
jednake značajke, a ovdje će se donijeti potvrde neprefigiranih oblika prema licima, potvrđenim u temporalu $\mathrm{BrBer}_{2}$.

1. lice jd. svih potvrđenih glagola ima nastavak -mb / -m': esm' $86 \mathrm{~d} / 27$, es(a)m'31c/26, imb 109a/4, 109a/7, êmb 109b/31; dam'38c/26, 40b/8, 99d/11 $\mathrm{i}$ dr., damb $10 \mathrm{c} / 33,11 \mathrm{~b} / 27,13 \mathrm{~b} / 33 \mathrm{i}$ dr.; imamb $86 \mathrm{~d} / 9,132 \mathrm{~d} / 18$, imam' $87 \mathrm{~d} / 27$, $111 \mathrm{a} / 6$; vêmb $75 \mathrm{c} / 28,170 \mathrm{~b} / 30 \mathrm{i}$ dr. Glagol vêdêti potvrđen je dvaput u obliku vêdê $30 \mathrm{~b} / 25,160 \mathrm{~d} / 10 \mathrm{u}$ kojem dolazi i u drugim hrvatskoglagoljskim liturgijskim tekstovima (HCSJ 2014: 216-217).

Svi su atematski glagoli, izuzev glagola imêti, u 2. licu jd. imali nastavak -si. Taj je nastavak potvrđen, ali u glagolima êsti, dati i vêdêti uza nj supostoji i nastavak -ši preuzet iz tematskih glagola i usto poduprt oblikom imaši atematskoga glagola imêti: iši 93a/3, 93a/19, 93a/21, jiši 217c/23; dasi 38c/29, 158a/3, 169a/17 i dr., daši 151d/22, 173c/23, 255d/1; vêši 150d/18, 209b/2, viši $103 \mathrm{a} / 10,109 \mathrm{a} / 17,145 \mathrm{a} / 32$, vesi $185 \mathrm{c} / 32$. Oblici s inovativnim nastavkom brojniji su i jasno upućuju na tendenciju njihova paradigmatskoga ujednačavanja prema tematskima koja je potvrđena i u drugim liturgijskim hrvatskoglagoljskim tekstovima (HCSJ 2014: 217). Ta je inovacija u organskim idiomima potvrđena vrlo rano (usp. LUKEŽIĆ 2015: 295) i evidentno je u pisani diskurs ušla iz govornoga medija. Glagol biti ima oblik esi $27 \mathrm{a} / 33,75 \mathrm{c} / 24,105 \mathrm{~d} / 30$, $175 \mathrm{c} / 34$ i dr., a glagol imêti ima imaši ${ }^{12}$ 9a/27, 38c/24, 72b/29 i dr.

U 3. licu jd. potvrđeni su normativni oblici: estb 20d/29 i dr., est' 24b/16, 26b/18 i dr., est 66c/1 i dr., e 17d/12, 53a/15, 160a/15 i dr.; êstb 109c/1, 111a/8 i dr.; dastb $2 \mathrm{c} / 17 \mathrm{i} \mathrm{dr}$; imatb $6 \mathrm{c} / 4 \mathrm{i}$ dr., ima $262 \mathrm{~d} / 16 \mathrm{i}$ dr.; vêstb $37 \mathrm{~d} / 3 \mathrm{i} \mathrm{dr}$., vêst' $21 \mathrm{~b} / 27 \mathrm{i}$ dr., vêst $236 \mathrm{~d} / 22$, vist' $92 \mathrm{c} / 32$, vêst $236 \mathrm{~d} / 22$. Potvrđen je oblik e glagola biti koji, izvjesno je po pozicijama u rečenici, ima funkciju nenaglašenoga. Taj se oblik najčešće potvrđuje u rubrikama. Glagol imêti u 3. licu jd. dolazi i bez dočetnoga $-t$, s time da su te potvrde ovjerene samo u rubrikama.

Od dvojinskih oblika potvrđeno je: 1. lice dv.: es'vê 156a/20, 156a/24; es'va 50b/21; jiva 92c/26; 2 . lice dv.: es'ta 37b/29, 162a/29; 3. lice dv.: es'ta 39a/17; imata 38b/5 i dr. U 2. i 3 . licu dvojine je nastavak -ta, dok se u 1. licu, uz stariji nastavak -ve realizira i - va s podjednakom distribucijom. Budući da je u tematskih glagola samo jedna potvrda oblika s nastavkom - $v a$, moguće je pretpostaviti da do paradigmatskoga ujednačavanja dočetnoga nastavačnoga vokala najprije dolazi u atematskih glagola pa se ono naknadno širi na tematske.

${ }^{12}$ Glagol je potvrđen i u obliku imeeši 132a/33 u kojem se ponaša kao tematski glagol 9. A razreda koji je bio vrlo produktivan. 
U svih su glagola u 1. licu mn. potvrđeni i oblici s nastavkom -mo, s time da su u glagola biti i imêti pretežiti: esmb $155 \mathrm{c} / 7$ i dr., esbmb $44 \mathrm{a} / 12 \mathrm{i}$ dr., esmo 3b/24, 66c/8 i dr.; imam' $87 \mathrm{~d} / 27$ i dr., imamo $159 \mathrm{c} / 19$ i dr.; vêmb $36 \mathrm{~d} / 14$ i dr., vim' $180 \mathrm{c} / 24$ i dr., vêmo $214 \mathrm{~b} / 33$. Samo je jedna potvrda toga oblika glagola dati i glasi damo 263b/32, a potvrđena je u rubrici. U dvjema pojavnicama dolazi u obliku dademb (103b/11 i 105b/19). U 2. licu mn. potvrđeni su oblici este, êste, daste, vêste, vis'te, a u 3. licu mn. uz još uvijek pretežit sutb / sut' potvrđen je i su. Taj je oblik potvrđen ukupno deset puta, ali samo dvaput dolazi izvan rubrika. U 3. licu mn. glagoli dati i vêdêti imaju dvojne oblike pa se osim normom hrvatskoga crkvenoslavenskoga jezika propisanoga nastavka -etb potvrđuje i -ut: dadut' $245 \mathrm{~d} / 1$ i dadetb $261 \mathrm{~b} / 26$ te vêdut $62 \mathrm{a} / 23$ i vêdêt' $133 \mathrm{c} / 33$. Do proširenja nastavka -utb vjerojatno dolazi zbog utjecaja paradigme tematskih glagola. Glagol imêti ima samo oblik imutb 27c/8.

Inovacije u prezentu atematskih glagola odnose se na širenje nastavka $-s ̌ i$ u 2. licu jd. glagola êsti, dati i vêdêti kao rezultat paradigmatskoga ujednačavanja prema tematskim glagolima, poduprt stanjem u govornom diskursu. $\mathrm{U}$ rubrikama su potvrđene inovacije u 3. licu jd. te se javlja nenaglašeni oblik glagola biti, dok su u 3. licu mn. potvrđeni nastavci s dočetnim -tb, ali se širi nastavak -utb, prema paradigmi tematskih glagola. U 1. licu mn. nastavak -mo češći je no u tematskih glagola.

\section{IMPERATIV}

Imperativ je glagolski način koji se u hrvatskom crkvenoslavenskom jeziku potvrđuje u dvjema formama, kao jednostavni ili sintetski te složeni ili analitički, tvori se od prezentske osnove, a njime se izražava naredba, zabrana, zahtjev, savjet ili molba (HCSJ 2014: 219). S obzirom na prirodu imperativnoga značenja, najčešći su oblici 2. lica jd. i mn., a pretežu množinski oblici. Iako su predmet zanimanja u ovom prilogu jednostavni glagolski oblici, ponudit će se i osnovne značajke analitičkoga imperativa, radi cjeline opisa ovoga glagolskoga načina. 


\subsection{Jednostavni (sintetski) oblici imperativa ${ }^{13}$}

Kao i u drugim hrvatskoglagoljskim tekstovima i u temporalu $\mathrm{BrBer}_{2}$ potvrđeni su glagoli s izmijenjenim osnovama, a specifični su glagoli čija osnova završava ili je završavala velarnim suglasnikom jer se u njima događaju dva tipa izmjena: 1. na dočetku osnove dolazi do druge palatalizacije; 2 . korijenski se vokal e zamjenjuje poluglasom, a on dalje vokalom $a$. Tako je od glagola teĉi potvrđen oblik tacite $164 \mathrm{~b} / 14 \mathrm{u}$ kojem je vokal a mogao nastati samo od vokalizacije slaboga poluglasa. Glagol reĉi ima imperativnu osnovu $r b c-: r^{\prime} c i$ 5a/22 i dr.; r'cimo 226b/23 i noviju rec-: $r($ e) cite $59 \mathrm{~d} / 28 \mathrm{i} \mathrm{dr}$.

U 2. licu jd. na osnove koje završavaju suglasnikom dolazi nastavak $-i$ : veseli $11 \mathrm{c} / 24,124 \mathrm{c} / 2$; vezi $216 \mathrm{a} / 28$; vihiti $66 \mathrm{~b} / 33,206 \mathrm{a} / 3 \mathrm{i} \mathrm{dr}$., a na osnove koje završavaju samoglasnikom nastavak $-j$ koji se bilježi grafemom $i$ : otpuĉai $230 \mathrm{c} / 9$; pokai $172 \mathrm{a} / 21,172 \mathrm{c} / 17 ; 7 \mathrm{a} / 4 \mathrm{i} \mathrm{dr}$. i u jednoj potvrdi grafemom $\hat{j}$ : pijb 233b/22. Zabilježeni su oblici imperativa atematskih glagola: dai 19d/15, 68d/17, 76c/17 i dr., daĵb 198a/11; imêi 233b/25, 234b/1 i dr.; êjb 217d/1, snijb 255a/3. Glagoli izêsti, vêdêti i njegove izvedenice te glagol vidêti i od njega izvedeni glagoli $\mathrm{u}$ analiziranom tekstu tvore imperativ i tako da dolazi do jotacije dočetnoga konsonanta osnove: povêžd' 38c/21; v(i)ždb 173c/2; izêžd 175a/28. Međutim, glagoli vidêti i vêdêti, osim oblika sa starocrkvenoslavenskim refleksom jotacije imaju i oblike s čakavskim refleksom: vijb 204d/2, $204 \mathrm{~d} / 13,250 \mathrm{~b} / 27$ (< vidêti) te povêi $12 \mathrm{a} / 31$ i povii $259 \mathrm{c} / 26$ (< vêdêti). U analiziranom tekstu nije potvrđen oblik s jotiranom osnovom glagola dati (dažd', $d a z ̌ d b)$.

Potvrđeni su i sintetski oblici za 3. lice jd., s nastavkom -i.

Svi množinski i dvojinski oblici imperativa imaju podudarnu strukturu i jednake tendencije. U njihovoj se tvorbi izdvajaju, za praćenje izmjena i utvrđivanje odstupanja od norme crkvenoslavenskoga jezika relevantni imperativni formanti. $U$ analiziranom je tekstu sustavno narušena izvorna raspodjela imperativnoga formanta u imperativnim oblicima: u $e$-glagola potvrđeni su oblici s formantom $-i-$, a u $i$-glagola oblici s formantom $-e-/-\hat{e}-$, s time da je prva situacija u svim licima češća od druge.

\footnotetext{
${ }^{13}$ Ana Šimić i Jozo Vela bavili su se analizom odnosa vida i pravoga jednostavnoga niječnoga imperativa na istom korpusu te su utvrdili da je uporaba vida neovisna o latinskom predlošku i zaključili: »U zadanom su pak korpusu nesvršeni pravi niječni imperativi u blagoj prednosti, ali ne držimo da je to zasada dovoljno da bi se utvrdio neosporan početak povlačenja svršenoga vida« (ŠIMIĆ; VELA 2018: 184).
} 
Dvojinski su oblici relativno rijetki. U 1. licu dv. samo su dvije potvrde: poidive $93 \mathrm{c} / 1$ i vzidêvê $9 \mathrm{~d} / 17$. U 2. licu dv. prevladava nastavak -ita i u glagola $i$-tipa i u glagola e-tipa: obladaita $91 \mathrm{~d} / 20$; vladaita $91 \mathrm{~d} / 19$; ras'tita $91 \mathrm{~d} / 18$ i dr. Nastavak -êta rjeđi je, a glagol iti ima oba oblika idita $263 \mathrm{~d} / 27$ i idêta 141a/27. Samo su dvije potvrde za 3. lice dv.: budita 82c/2 i hranita 234a/16 i potvrđuju poopćavanje nastavka -ita na sve glagole.

U 1. licu mn. potvrđeni su primjeri s očekivanim i normom crkvenoslavenskoga jezika propisanim nastavcima (tipa padêmb 39b/23, lûbimo 98a/4, poklonimb $51 \mathrm{~b} / 28 \mathrm{i}$ dr.), ali i oni u kojima je došlo do zamjene formanata pa je potvrđen imperativni formant $-i$ - i u glagola $e$-tipa (naidimo $211 \mathrm{~b} / 9 \mathrm{i} \mathrm{dr}$.), ali i formant -êm- / -em- u glagola $i$-tipa (poklonêmb 58a/16 i dr.). Nastavci množinskih i dvojinskih oblika imperativa jednaki su nastavcima prezenta pa se u dvama glagolskim oblicima očekuju i iste promjene. U temporalu $\mathrm{BrBer}_{2}$ potvrđeni su nastavci - mb i - mo, kao u prezentu, no u imperativu su, za razliku od prezenta, pretežiti oblici s nastavkom -mo.

Izuzetno su brojni oblici 2. lica mn., a velik broj glagola ima dubletne oblike: poopćavanje na -ite: izidête $25 \mathrm{a} / 31$ i izidite $178 \mathrm{~b} / 31$; icête $2 \mathrm{~b} / 30$ i icite $8 \mathrm{~b} / 31$; r'cête $28 \mathrm{~b} / 8$ i rcite $1 \mathrm{c} / 9$; poopćavanje na -ête: obratite $104 \mathrm{c} / 18$ i obratête $23 \mathrm{~d} / 7$; poklonite 58a/29 i poklonête 31a/20; smotrite $1 \mathrm{~d} / 21 \mathrm{i}$ smotrête $139 \mathrm{a} / 27 \mathrm{i} \mathrm{dr}$.

Tendencija poopćavanja nastavaka zabilježena je i u svim drugim hrvatskoglagoljskim tekstovima (HCSJ 2014: 221). Usprkos potvrdama dvosmjernoga poopćavanja, u temporalu BrBer $_{2}$ učestalije je ujednačavanje u glagola $e$-tipa na nastavke s formantom - $i$ - nego obrnuto. Specifična je i pretežitost nastavka -mo u 1. licu mn. dok u prezentu prevladavaju oblici sa starijim nastavkom. Potvrđeni su i oblici 3. lica jd.

\subsection{Složeni (analitički) oblici imperativa}

Imperativnost se često izražavala s više riječi. U ovom tekstu, ali i u drugim hrvatskoglagoljskim tekstovima (HCSJ 2014: 224-226) tvori se na ove načine:

- od čestice da i oblika prezenta glagola: ovaj je način izricanja u tekstu rijedak, a kada je potvrđen, najčešće je u 3. licu jd.: da isplnit se $r(e)$ č(e)noe $\operatorname{pr}(o) r(o) k(o) m b 55 \mathrm{c} / 12$; ni oči da ne sagrêšets oskvr'nêniemb - i têlese zloboû da ne oskvr'nit se 80b/2; 3. licu mn.: semene semenita po rodu svoemu da budutb vamb v piĉu $i$ v'simb dišsucimb na z(e)mli v nihbže e (stb) $d(u)$ ša živuciêe da imutb $91 \mathrm{~d} / 29-31$ i najrjeđe u 1. licu mn.: da plod' primemo ot nee $229 \mathrm{~d} / 25$ ); 
- konstrukcijom od zanijekanoga imperativa mozi glagola moĉi i infinitiva: 2. lice jd.: sione ne mozi boêti se da skoro pridetb $2 \mathrm{c} / 23$; grade er(u)s(oli)me ne mozi plakati $10 \mathrm{~d} / 31 ; 2$. lice $\mathrm{mn} .:$ rehb vamb ne mozite sagrešiti v' otroci $117 \mathrm{a} / 19 \mathrm{i}$ dr.;

- konstrukcijom od zanijekanoga glagola hotêti i infinitiva: 2. lice jd.: ne hotêi prêzreti $d(u)$ še moee $212 \mathrm{~d} / 19$; $i$ ne hotêi me otvrêci ot otrokovb 231a/26; 2. lice mn.: ne hotêite prêje vrêmene suditi 23b/30-32; ne hotêite naveĉati 209c/15; ne hotêite poslati e 213c/13; ne hotêite pečal'ni biti 222d/6; ne hoteite priêti bêžaniê 243b/20 i dr.

\section{AORIST}

Aorist je nedvojbeno jedan od najbrojnijih oblika u hrvatskoglagoljskim tekstovima pa tako i u ovdje analiziranom. Velikoj većini glagola, gotovo 88\% (HCSJ 2014: 234) u hrvatskom crkvenoslavenskom jeziku infinitivna osnova završava vokalom i oni tvore aorist po modelu sigmatskoga 1. aorista. Manjem broju glagola infinitivna osnova završava konsonantom i oni mogu, ovisno o vrsti, tvoriti asigmatski, sigmatski prvi i sigmatski drugi aorist (HCSJ 2014: 234).

\subsection{Asigmatski aorist}

U tekstu temporala $\mathrm{BrBer}_{2}$ potvrđeni su sljedeći oblici asigmatskoga aorista: 1. lice jd.: pribêgb 20a/10; prid'239b/4, 239b/16; vznês' $1 \mathrm{c} / 32$; v'zdvigb 72d/31; 2. lice jd.: pobêže $62 \mathrm{c} / 1$; vnide $3 \mathrm{a} / 24$; 3 . lice jd.: dviže $203 \mathrm{c} / 34$ / razdviže $93 \mathrm{c} / 11$; ide 14d/14; pomože 176a/21, vzmože 49b/7, 131d/32; prinese 39b/29, 75a/29; 1 . lice $\mathrm{mn}$.: pridomb $58 \mathrm{a} / 10,58 \mathrm{~b} / 12,61 \mathrm{a} / 7$; obrêtomb $151 \mathrm{~d} / 11$; utegomb $50 \mathrm{~d} / 11$; 3. lice mn.: is 'seku 97a/14; napadu 145d/31, 249a/4; obrêtu 48d/24, 151b/24; obidu $142 \mathrm{a} / 22$, a nema potvrda za dvojinske oblike i 2 . lice mn.

U kanonskim su tekstovima potvrde asigmatskoga aorista rijetke i sporadične dok su u temporalu BrBer ${ }_{2}$, kao i u ostalim liturgijskim hrvatskoglagoljskim tekstovima potvrde ipak brojnije (HCSJ 2014: 236). Gledaju li se potvrdnice, evidentna je kumulacija asigmatskih aorista po pojedinim tekstnim cjelinama dok ih u drugima uopće nema. To svakako upozorava na specifičan $i$ arhaičan tekstni predložak. ${ }^{14} \mathrm{~S}$ obzirom na njegovu arhaičnost i na činjenicu

${ }^{14}$ Jedan od starijih predložaka s kojih je mogao biti prepisan najvjerojatnije potječe s otoka Krka (MIHALJEVIĆ 2011: 138; HCSJ 2014: 42). 
da je potvrđen samo u kasnijim književnim tekstovima visoke stilizacije te da nije zabilježen u organskim idiomima (LUKEŽIĆ 2015: 322-323), vjerojatno on nikada nije bio dio govornoga, čakavskoga diskursa.

\subsection{Sigmatski 1. aorist}

\subsubsection{Osnove koje završavaju samoglasnikom}

U temporalu $\mathrm{BrBer}_{2}$ potvrđeni su sljedeći oblici jednine i dvojine: 1. lice jd.: hotêhb 86b/22; is 'sahb 82c/21, 239d 19; rodihb 1c/32, 33d 3; usnuhb 158b/26 i dr.; 2. lice jd.: nas 'ledova 130c/5; oblada $7 \mathrm{a} / 18 \mathrm{i}$ dr.; 3 . lice jd.: sazda 91c/20, 92c/2; doposti (!) 242d/29; iscêlê $29 \mathrm{c} / 1 \mathrm{i} \mathrm{dr}$; 1 . lice dv.: poslasve $242 \mathrm{~d} / 2$; obidos'vê $37 \mathrm{~b} / 14$; 2 . lice dv.: otlučista $37 \mathrm{c} / 6$; slišasta $12 \mathrm{~d} / 30$; pogubista 37c/11 i dr; 3 . lice dv.: naučista $68 \mathrm{c} / 26,69 \mathrm{a} / 2 ;$ skrista $92 \mathrm{~d} / 14$; čusta $63 \mathrm{~b} / 23$; stasta $167 \mathrm{c} / 1,175 \mathrm{c} / 7 \mathrm{i}$ dr. U 1 . licu dv. potvrđen je samo nastavak -sve nastao ujednačavanjem prema tvorbenom modelu 2. lica mn., a stariji nastavak -hove nije potvrđen. Oblici 2. i 3. lica dvojine imaju isti nastavak -sta što je inovacija potvrđena i u svim ostalim hrvatskoglagoljskim tekstovima.

U 1. licu mn. supostoje nastavci -homb i -smo: verovahomb 90a/10; sadêehomb 228d/21, 243b/22; položihomb 17b/3 i dr.; molis'mo 257a/31; razumis'mo $127 \mathrm{c} / 22$; dopustismo $72 \mathrm{~d} / 21$; vzbranismo $65 \mathrm{~d} / 22 \mathrm{i}$ dr., s time da je - smo rjeđi. U 2. licu mn. potvrđen je nastavak -ste: videste 63a/13, 166a/14; ubis'te 35c/2, 35c/16 i dr.; a u 3. licu mn. -še: iz'liêše 143c/18, 151b/33; dovedoše $140 \mathrm{~b} / 21,212 \mathrm{a} / 31 \mathrm{i} \mathrm{dr}$.

Nastavci za 1. lice mn. -smo i 1. lice dv. -sve inovativni su oblici za 1. lice nastali kao rezultat tendencije paradigmatskoga ujednačavanja prema oblicima za 2. lice mn. (-ste) te 2. i 3. lice dv. (-sta). Pojava je to opisana i potvrđena i u drugim hrvatskoglagoljskim tekstovima ne samo liturgijskoga tipa (HCSJ 2014: 234-235).

\subsubsection{Osnove koje završavaju suglasnikom}

Ovi se oblici tvore na specifičan način pa osnova ovoga aorista nerijetko biva znatno izmijenjena u odnosu na polazišnu, infinitivu osnovu. Razlog je to zbog kojega su ovi oblici bili stilogeni. U analiziranom su tekstu potvrđeni sljedeći oblici: ${ }^{15}$ 1. lice jd.: narêhb 16d/17, rêhb 148c/6, 152b/13, 189b/14; 3 .

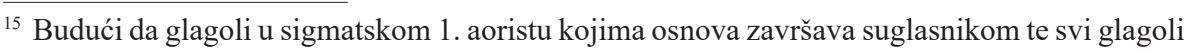
u sigmatskom 2. imaju u 2. i 3 . licu. jd. oblik preuzet iz asigmatskoga, ovdje se neće izdvajati. 
lice dv.: rêsta $162 \mathrm{c} / 6,162 \mathrm{c} / 13$; 1 . lice mn.: rêhomb 53b/17, 59b/25; rês'mo $225 \mathrm{~d} / 20$; 2. lice $\mathrm{mn} .:$ rêste $17 \mathrm{a} / 32$, riste $261 \mathrm{~d} / 19$; 3. lice mn.: reše $173 \mathrm{c} / 24$, $188 \mathrm{~b} / 19$; probose $169 \mathrm{~d} / 24$.

Svi su potvrđeni oblici tvoreni na očekivan način, uz određene fonološke izmjene. Novije je jezično stanje potvrđeno samo u obliku za 1. lice mn. gdje se, uz stariji -homb, potvrđuje nastavak -smo koji je u ostalim hrvatskoglagoljskim tekstovima rjeđi, ali ipak potvrđen, primjerice u Drugome novljanskom brevijaru: rês'mo (HCSJ 2014: 239). Oblik 3. lica mn. probose (<-basę) ima korijenski vokal $o$, a pretpostavlja se da je on posljedica kontaminacije oblikom sigmatskoga drugoga aorista (probodošę) koji dolazi na tom mjestu u ostalim misalima. Potvrđen je brojnim hrvatskoglagoljskim misalima (HCSJ 2014: 239).

\subsection{Sigmatski 2. aorist}

Sigmatski 2. aorist je značajka mlađih tekstova i u starijim ga kanonskim tekstovima nije bilo. Prema HCSJ (2014: 240) nije čest ni u drugim liturgijskim tekstovima, a smatra se utjecajem govornoga jezika. I u temporalu BrBer $_{2}$ malobrojne su potvrde: 1 . lice jd.: mogohb 84b/19; otvr'goh' 233b/16; privedohb 13c/15; tekohb 89c/20; 3. lice dv.: pridosta 167d/5, 213a/26; otvr'gosta 38a/31; padosta 209a/34; 1. lice mn.: ponesohomb 155c/16.

U 1. licu jd. aorista glagola biti pet je potvrda oblika bihb, dok je bêhb, bêh' potvrđen 12 puta $(2 \mathrm{c} / 8,40 \mathrm{c} / 9,140 \mathrm{c} / 5,89 \mathrm{c} / 4 \mathrm{i}$ dr.). Potvrđena su četiri oblika 3. lica jd. aorista glagola biti. Najbrojniji su bi 35a/5 i dr. i bê 176a/26 i dr., be 46a/16 i dr. Nešto je rjeđi bistb, bist', bist 186b/21, 250a/21, 27a/19, $140 \mathrm{~d} / 21$ i dr., a za hrvatski crkvenoslavenski jezik specifičan oblik bisi potvrđen je samo četiri puta $(52 \mathrm{~b} / 9,62 \mathrm{~d} / 3,114 \mathrm{a} / 5,114 \mathrm{a} / 19)$. U 1 . licu mn. prevladava oblik bihomb $118 \mathrm{~d} / 7 \mathrm{i}$ dr., bihom 190d/2 i dr., a bêhomb $138 \mathrm{~b} / 27 \mathrm{je}$ potvrđen samo jednom. I u 2. licu mn. postoji dvojnost bêste, biste, s time da je bêste potvrđeno samo jednom (13d/21). U 3. licu mn. distribucija oblika s osnovama bih- i bêh-ima obrnutu tendenciju i višestruko prevladavaju oblici s osnovom biš- (biše 975, a bêše 249).

Prošla se radnja u temporalu BeBer ${ }_{2}$ najčešće izražava aoristom, a zbog strukture samih glagola najčešći su sigmatski prvi aoristi u glagola kojima osnova završava vokalom. U analiziranom su tekstu potvrđena sva tri oblika aorista. U dvama sigmatskim aoristima, od inovativnih jezičnih značajki ističe se pojava nastavka -smo u 1. licu mn. uz pretežito zadržavanje starijega nastavka -homb, što je potvrđeno u i ostalim liturgijskim tekstovima pisanim 
hrvatskim crkvenoslavenskim jezikom, dok je u 1. licu dv. sigmatskoga 1 . aorista ovjeren nastavak -sve. Oba nastavka predstavljaju inovacije, a nastali su kao rezultat tendencije paradigmatskoga ujednačavanja prema oblicima 2. lica mn. (-ste) te 2. i 3. lica dv. (-sta).

\section{IMPERFEKT}

Uz aorist, prošla se radnja izražavala imperfektom. Najčešće se tvori od nesvršenih glagola i to tako da se na prezentsku ili infinitivnu osnovu dodaje formant $-\hat{e} a{ }^{16}{ }^{16}$ koji se iza palatala preglašava $u-a a-$.

$\mathrm{U}$ tekstu prevladavaju oblici s kontrahiranim slijedom $\hat{e} a>a$ (lûblahb 151c/27; prostirahb 231a/9 i dr.), a nekontrahirani je slijed potvrđen samo u primjerima: s'mêrêêhb 133d/18; bolêaše 226d/1, bolêêše 144d/12, 144d/17, boleêše 127c/15, 127c/20; dov'lêaše 39d/30; dêlêaše 39d/30; gredêêše 20d/18, 253d/29, grêdêê̌se 253c/24; pitêê̌e 134c/4; idêeše 37a/17, 89d/24; mnêêse 62b/11; hotêê̌se 137c/6; rastêêse 34a/32; rasteêše 49a/16; sadeêhomb 185d/24, 254b/24; piteêhu 155b/9. Potvrđene su i dublete: mnêêše i mnêše; bolêaše i boliše, a ni jednom nije potvrđen oblik bêaše glagola biti. Nekontrahirana osnova - $a a$ - nije potvrđena u temporalu.

Od ukupno 665 pojavnica različitih oblika glagola u imperfektu, samo je 16 pojavnica s nekontrahiranom osnovom, s ukupno 21 potvrdom, a to čini $2,4 \% .{ }^{17}$ Glavnina je glagola nekontrahirane osnove u 3. licu jd. I u tom segmentu temporal BrBer $_{2}$ potvrđuje sukladnost s normom hrvatskoga crkvenoslavenskoga jezika (HCSJ 2014: 244).

U jednini potvrđeni su nastavci -hb (1. lice) i -še (2. i 3. lice). Samo je jedna potvrda oblika za 1 . lice $\mathrm{dv}$. i to sa starijim nastavkom -hove (isk(a)hovê 65a/7). U 2. licu dv. nastavak je -šeta (cêlašeta 37c/14; v'daêšeta 37c/16 i dr.),

${ }^{16} \mathrm{U}$ hrvatskom crkvenoslavenskom jeziku, ali i u temporalu BrBer $_{2}$ ovaj se formant često bilježi kao -êe-, najčešće u glagola kojima je infinitivna osnova završavala jatom (HCSJ 2014: 224).

${ }^{17}$ Računalni program ekscerpira samo pojavnice, a svaka pojavnica može u tekstu imati i više potvrda. To znači da je broj potvrda pojavnica imperfekta veći od 665, a broj potvrda 16 pojavnica s nekontrahiranom osnovom također veći (21). Za preciznu kvantitativnu analizu bilo bi potrebno navesti točan broj potvrda imperfekta u tekstu i usporediti ga s točnim brojem potvrda s nekontrahiranom osnovom. Budući da cilj ovoga istraživanja nije precizna kvantitativna analiza, ovdje se postotak izvodi uspoređujući broj pojavnica imperfekta (665) i broj pojavnica imperfekta s nekontrahiranom osnovom (16). Postotak izveden iz odnosa broja potvrda bio bi još manji. 
a isti je u dvjema pojavnicama potvrđen i u 3 . licu (poslêdovašeta 37a/16; b(ê)šeta 38b/24) dok prevladava noviji nastavak -hota (isk(a)hota 63b/25; mnêhota 63b/24 i dr.) nastao ujednačavanjem prema 1 . licu mn., što je ovjereno i u drugim hrvatskoglagoljskim tekstovima (HCSJ 2014: 244).

U 1 . licu mn. prevladava nastavak -homb: požidahomb 16c/26, 18b/9; ufahomb $7 \mathrm{a} / 10 \mathrm{i} \mathrm{dr}$.), a samo je jednom potvrđen oblik nošahomo $155 \mathrm{c} / 20 \mathrm{u}$ kojem se nastavačni dočetak ponaša po obrascu sličnoga nastavka u prezentu te se dočetna sekvencija - $m b$ zamjenjuje s - $m o$, što je nedvojbeno utjecaj govorne čakavštine. ${ }^{18}$ Novi nastavak -hote jedini je potvrđen u 2. licu mn.: bêhote 138c/27, 149a/11; g(lago) lahote 22b/16 i dr., a nema potvrde oblika s nastavkom -šete. Nastavak je potvrđen i u drugim liturgijskim hrvatskoglagoljskim tekstovima, ali samo u konjugaciji glagola moĉi: možahote $\mathrm{BrVb}_{1} 78 \mathrm{c}$; $\mathrm{BrVat}_{5}$ 60b; BrVO 104a; $\mathrm{BrVb}_{3} 43 \mathrm{a} ; \mathrm{BrN}_{1}$ 60d (HCSJ 2014: 246). U 3. licu mn. očekivano je - $h u$, a samo u dvjema pojavnicama -ho: gl(agola)ho 193a/5 i možaho $133 \mathrm{~b} / 7$. Potonja bi se pojava mogla opisati kao utjecaj središnjih istarskih govora u kojima je moguć refleks $o$ od stražnjega nazala, koji je u govoru Berma i »danas dosljedan u gramatičkim morfemima« (VRANIĆ 2020: 279) no ne treba isključiti ni mogućnost da se radi o prepisivačkoj pogrešci proizišloj iz sličnosti glagoljskih grafema $o$ (马) i $u$ (刃) (MIHALJEVIĆ 2011: 131). Dijelove rukopisa u kojima su potvrđeni ti primjeri pisali su različiti pisari pa je, pretpostavimo li da se radi o utjecaju iz konkretnoga mjesnoga govora, to potvrda da su neki pisari u skriptoriju bili govornici istoga ili sličnoga lokalnoga idioma.

U imperfektu prevladavaju kontrahirane osnove. Od morfoloških inovacija u imperfektu izdvaja se supostojanje nastavaka -hota i -šeta u 3. licu dv., uz pretežitost novijega -hota koji je analoški prema 1. dv. -hovê. U jednom primjeru 1. lica mn. potvrđen je nastavak -homo, a specifično je da su u 2. licu $\mathrm{mn}$. brojnije potvrde novijega, analoškoga nastavka -hote. Tendencija ujednačavanja dvojinskih i množinskih oblika na formant $h$ može biti rezultat nastojanja da se istakne razlika prema aoristu.

\footnotetext{
${ }^{18}$ Oblici s tim nastavkom i danas su potvrđeni u rijetkim ikavsko-ekavskim čakavskim govorima na kvarnerskim otocima u kojima se još čuva imperfekt (LUKEŽIĆ 2015: 324).
} 


\section{ZAKLJUČAK}

Morfologija jednostavnih glagolskih oblika u temporalu Drugoga beramskoga brevijara najvećma je podudarna s opisanom normom hrvatskoga crkvenoslavenskoga jezika, a i sva se popisana odstupanja potvrđuju i u ostalim liturgijskim tekstovima. Divergirajući su elementi najčešće preuzeti iz govorne čakavštine ili su nastali kao rezultati paradigmatskoga ujednačavanja. Dvojina se kao kategorija još uvijek dobro čuva, a u svim je glagolskim oblicima sustavno zabilježeno ujednačavanje 2. i. 3. lica dv. na dočetno - $t a$.

U morfologiji prezenta tematskih glagola odstupanja su sporadično potvrđena u 1. licu jd., te 3. licu jd. i mn., a najbrojnija je inovacija iz govornoga diskursa preuzet nastavak -mo, iako prevladavaju oblici sa starijim nastavkom $-m b /-m^{\prime} /-m$. U prezentu atematskih glagola potvrđen je oblik vêdê u 1. licu jd. glagola vêdêti, utvrđeno je širenje nastavka -ši u 2. licu jd. glagola êsti, dati i vêdêti, a u rubrikama su potvrđene inovacije u 3. licu jd. te se javlja nenaglašeni oblik glagola biti. U 3. licu mn. potvrđeni su nastavci s dočetnim -tb, ali se širi nastavak -utb, prema paradigmi tematskih glagola. U 1. licu mn. nastavak -mo češći je no u tematskih glagola.

Usprkos potvrdama dvosmjernoga poopćavanja imperativnih formanata (-e-/-ê- > $-i-\mathrm{i}-i->-e-/-\hat{e}-)$, u množinskim je i dvojinskim oblicima sintetskoga imperativa temporala $\mathrm{BrBer}_{2}$ učestalije ujednačavanje na formant $-i$ - Specifična je pretežitost nastavka -mo u 1 . licu mn. dok u prezentu prevladavaju oblici sa starijim nastavkom, a potvrđeni su i oblici 3. lica jd.

$\mathrm{U}$ analiziranom su tekstu potvrđena sva tri aorista. U dvama sigmatskim aoristima, od inovativnih jezičnih značajki ističe se pojava nastavka -smo u 1. licu mn. uz pretežito zadržavanje starijega nastavka -homb /-hom' /-hom, što je potvrđeno i u ostalim liturgijskim tekstovima pisanim hrvatskim crkvenoslavenskim jezikom, dok je u 1. licu dv. sigmatskoga 1. aorista ovjeren nastavak -sve. Oba nastavka predstavljaju inovacije, a nastali su kao rezultat tendencije paradigmatskoga ujednačavanja prema oblicima 2. lica mn. (-ste) te 2. i 3 . lica dv. (-sta).

U imperfektu prevladavaju oblici s kontrahiranim osnovama. Inovacija je supostojanje nastavaka -hota i -šeta u 3. licu dv., uz pretežitost novijega -hota koji je analoški prema 1. licu dv. -hovê. U jednom primjeru 1. lica mn. potvrđen je nastavak -homo, a specifično je da su u 2. licu mn. brojnije potvrde novijega, analoškoga nastavka -hote. 


\section{IZVORI}

BADURINA STIPČEVIĆ, V. i dr. 2015. = BADURINA STIPČEVIĆ, V.; I. BOTICA; M. DIMITROVA; M.-A. DÜRRIGL; I. HRISTOVA ŠOMOVA; A. KOVAČEVIĆ; K. KUHAR; M. MIHALJEVIĆ; Lj. MOKROVIĆ; S. POŽAR; A. RADOŠEVIĆ; M. ŠIMIĆ; J. VELA; J. VINCE; J. VUČKOVIĆ; S. ZUBČIĆ; M. ŽAGAR. 2015. Preslovljeni Temporal Drugoga beramskog (ljubljanskog) brevijara. Zagreb: Staroslavenski institut. URL: https://beram.stin.hr/hr/transliteration/ 53/1 (višekratno tijekom 2019. i 2020.).

BADURINA STIPČEVIĆ, V. i dr. 2018. = BADURINA STIPČEVIĆ, V.; I. BOTICA; M. DIMITROVA; M.-A. DÜRRIGL; I. HRISTOVA ŠOMOVA; K. KUHAR; M. MIHALJEVIĆ; S. POŽAR; A. RADOŠEVIĆ; A. ŠIMIĆ; M. ŠIMIĆ; J. VELA; J. VINCE; J. VUČKOVIĆ; S. ZUBČIĆ; M. ŽAGAR. 2018. Drugi beramski brevijar: hrvatskoglagoljski rukopis 15. stoljeća, 1. dio, sv. 2: transliteracija. M. Mihaljević (prir.). Zagreb: Staroslavenski institut.

\section{KRATICA IZVORA}

BrBer $_{2}$ - Drugi beramski brevijar, 15. st., Ljubljana, Narodna in univerzitetna knjižnica, sign. Ms 163.

\section{LITERATURA}

BADURINA-STIPČEVIĆ, V.; M. MIHALJEVIĆ; M. ŠIMIĆ. 2012. Mjesto Dabarskoga brevijara među hrvatskoglagoljskim liturgijskim kodeksima. H. Gračanin; Ž. Holjevac (ur.). Gacka i Otočac u srednjem vijeku. Zagreb - Otočac: Institut društvenih znanosti Ivo Pilar, Područni centar Gospić, 255-282.

CEKOVIĆ, B.; I. ETEROVIĆ. 2012. Dvojina u Misalu hruackome Šimuna Kožičića Benje. Fluminensia 24/1: 143-156.

CEKOVIĆ, B.; I. SANKOVIĆ; M. ŽAGAR. 2010. Jezik Misala hruackoga Šimuna Kožičića Benje: glagolski oblici. Slovo 60: 133-166.

DAMJANOVIĆ, S. 1982. Interferiranje hrvatskih dijalekata i općeslavenskoga književnoga jezika u hrvatskoglagoljskim tekstovima XV. stoljeća. Doktorski rad. Zagreb: Filozofski fakultet Sveučilišta u Zagrebu.

DAMJANOVIĆ, S. 2008. Jezik hrvatskih glagoljaša. Zagreb: Matica hrvatska.

GADŽIJEVA, S. 2012. Morfonologija prezentske paradigme u hrvatskome crkvenoslavenskom jeziku. Zagreb: Hrvatska sveučilišna naklada - Staroslavenski institut.

GALIĆ, J. 2014. Jednostavni glagolski oblici u Hrvojevu misalu. Slovo 64: 79-152.

GALIĆ, J. 2016a. Složeni glagolski oblici u Hrvojevu misalu. S. Botica; D. Nikolić; J. Tomašić; I. Vidović Bolt (ur.). Šesti hrvatski slavistički kongres: Zbornik radova sa 
znanstvenoga skupa s međunarodnim sudjelovanjem održanoga u Vukovaru i Vinkovcima od 10. do 13. rujna 2014. Zagreb: Hrvatsko filološko društvo, sv. 1, 3-13.

GALIĆ, J. 2016b. Jednostavni glagolski oblici u Hrvojevu misalu i Hvalovu zborniku. T. Kuštović; M. Žagar (ur.). Meandrima hrvatskoga glagoljaštva: Zbornik posvećen akademiku Stjepanu Damjanoviću o 70. rođendanu. Zagreb: Hrvatska sveučilišna naklada, 119-138.

HCSJ 2014. = GADŽIJEVA, S.; A. KOVAČEVIĆ; M. MIHALJEVIĆ; S. POŽAR; J. REINHART; M. ŠIMIĆ; J. VINCE. 2014. Hrvatski crkvenoslavenski jezik. M. Mihaljević (prir.). Zagreb: Hrvatska sveučilišna naklada - Staroslavenski institut.

HERCIGONJA, E. 1968. Jezik glagoljaške neliturgijske književnosti 15. stoljeća i Petrisov zbornik. Doktorski rad. Zagreb: Filozofski fakultet Sveučilišta u Zagrebu.

HERCIGONJA, E. 1999. Dvojina u jeziku tekstova hrvatskoglagoljičke neliturgijske književnosti XV. stoljeća: raščlamba građe iz Petrisova zbornika od 1468. i primjera iz 'Acta croatica'. Rasprave instituta za hrvatski jezik i jezikoslovlje 25: 123-140.

JURČEVIĆ, I. 2002. Jezik hrvatskoglagoljskih tiskanih brevijara. Osijek: Sveučilište Josipa Jurja Strossmayera u Osijeku.

JURČEVIĆ, I. 2004. Aktivni particip prezenta u hrvatskom crkvenoslavenskom jeziku. M.-A. Dürrigl; M. Mihaljević; F. Velčić (ur.). Glagoljica i hrvatski glagolizam. Zbornik radova s međunarodnog znanstvenog skupa povodom 100. obljetnice Staroslavenske akademije i 50. obljetnice Staroslavenskog instituta (Zagreb - Krk, 2.-6. listopada 2002.). Zagreb - Krk: Staroslavenski institut - Krčka biskupija, 607-616.

JURČEVIĆ, I.; R. TOLIĆ. 2011. Glagolski oblici u sanktoralu prvotiska hrvatskoglagoljskoga brevijara. Kroatologija 1/2: 95-109.

JUTRONIĆ, D. 2010. Spliski govor: od vapora do trajekta: po čemu će nas pripoznavat. Split: Naklada Bošković.

KUŠTOVIĆ, T. 2017. Glagolski oblici u protestantskom izdanju Artikuli ili deli prave stare krstianske vere (1562.). Slovo 67: 91-112.

LUKEŽIĆ, I. 2015. Zajednička povijest hrvatskih narječja. 2. Morfologija. Zagreb - Rijeka - Čavle: Hrvatska sveučilišna naklada - Filozofski fakultet u Rijeci - Katedra Čakavskoga sabora Grobnišćine.

MATASOVIĆ, R. 2008. Poredbenopovijesna gramatika hrvatskoga jezika. Zagreb: Matica hrvatska.

MIHALJEVIĆ, M. 2008. Glagolski oblici u hrvatskoglagoljskim fragmentima 12. i 13. st. Slovo 56-57: 333-349.

MIHALJEVIĆ, M. 2011. Bilješke o jeziku Drugoga beramskog brevijara. Tabula 9: 126139.

MIHALJEVIĆ, M. 2018. Jezik najstarijih hrvatskoglagoljskih rukopisa. Zagreb: Hrvatska sveučilišna naklada.

MIHALJEVIĆ, M.; J. VINCE. 2012. Jezik hrvatskoglagoljskih Pazinskih fragmenata. Zagreb - Pazin: Hrvatska sveučilišna naklada - Državni arhiv u Pazinu - Staroslavenski institut.

MILČETIĆ, I. 1911. Hrvatska glagoḷska bibliografija. I. dio: opisi rukopisa. Starine 33: $1-505$. 
REINHART, J. 1988. Eine Innovation bei der Aoristbildung im Kroatisch-Glagolitischen. Zeitschrift für slavische Philologie 48/2: 298-303.

ŠIMIĆ, A.; J. VELA. 2018. Dijakronijska analiza odnosa vida i pravoga jednostavnoga niječnog imperativa u hrvatskom jeziku. Fluminensia 2: 171-188.

ŠIMIĆ. M. 2014. Akademijin brevijar HAZU III c 12: hrvatskoglagoljski rukopis s konca 14. stoljeća: jezična studija, transliteracija, faksimil. Zagreb: Staroslavenski institut.

VAJS, J. 1910. Nejstarší breviář chrvatsko-hlaholský (Prvý breviáŕ Vrbnický). Praha: Král. Česká Společnost Náuk.

VRANIĆ, S. 2011. Govori sjeverozapadnoga makrosustava na otoku Pagu, 2. Morfologija. Novalja - Rijeka: Matica hrvatska, Ogranak Novalja - Filozofski fakultet Sveučilišta u Rijeci.

VRANIĆ, S. 2020. Jezične značajke temporala Drugoga beramskoga (ljubljanskoga) brevijara s gledišta povijesne dijalektologije. Slovo 70: 265-284.

VRANIĆ, S; S. ZUBČIĆ. 2015. Dialects in and around small urban centres in the northern Čakavian area: The current situation. A. Peti-Stantić; M.-M. Stanojević; G. Antunović (ur.). Language Varieties Between Norms and Attitudes - South Slavic Perspectives: Proceedings from the 2013 CALS Conference. Frankfurt am Main: Peter Lang Edition, 49-68.

ZUBČIĆ, S. 2003. Akcent glagolskoga pridjeva radnoga u sjeverozapadnim čakavskim govorima. Čakavska rič 1-2: 139-163.

ZUBČIĆ, S. 2015. Prilog proučavanju alternacija u osnovama glagola u Drugom ljubljanskom (beramskom) brevijaru [Temporal] $(\mathrm{d} / \mathrm{zd} / \mathrm{zg} \sim \check{\mathrm{z} d} \sim \hat{\mathrm{j}}$ i t/st/sk $\sim$ št $\sim \hat{\mathrm{c}})$. Ž. L. Levština (ur.). Десятые Загребинские чтения (29-30 октября 2015 года) материаль международной конференции. Санкт-Петербург: Российская национальная библиотека, 168-183.

ZUBČIĆ, S. 2016. Konsonantske alternacije u prezentskoj osnovi Temporala Drugoga beramskoga (ljubljanskoga) brevijara. T. Kuštović; M. Žagar (ur.). Meandrima hrvatskoga glagoljaštva: Zbornik posvećen akademiku Stjepanu Damjanoviću o 70. rođendanu. Zagreb: Hrvatska sveučilišna naklada, 569-584.

Sum mary

Sanja ZUBČIĆ

\section{SIMPLE VERB FORMS IN THE PROPER OF SEASONS OF THE SECOND BERAM BREVIARY}

This paper analyses the morphology of simple verb forms in the Proprium de tempore of the Second Beram Breviary: present, synthetic imperative, imperfect, and aorist. The data is compared with descriptions in Croatian Church Slavonic liturgical texts, including those features that, being introduced from vernacular Chakavian, deviate from the norm of Croatian Church Slavonic. 
The analysis has shown that the morphology of simple verb forms in the Proprium de tempore of the Second Beram Breviary is mostly consistent with the norm of Croatian Church Slavonic, with all listed deviations also being confirmed in other liturgical texts. Divergent elements most commonly originate from vernacular Chakavian or are the result of paradigmatic alignment. The category of the dual is still well preserved, and systematic alignment resulting in final $-t a$ is found in the $2^{\text {nd }}$ and $3^{\text {rd }}$ person.

The present forms of thematic verbs are found to occasionally deviate in the $1^{\text {st }}$ person $\mathrm{sg}$. and $3 \mathrm{rd}$ person sg. and pl., while the most frequent innovation from spoken language is the ending $-m o$, although forms with the older ending $-m b /-m ' /-m$ are the most prevalent. In the present tense of athematic verbs the ending $-s i$ is confirmed to have spread in the $2^{\text {nd }}$ person sg. of the verbs êsti ('eat'), dati ('give') and vêdêti ('see'), while innovations in the $3^{\text {rd }}$ person sg. and the unstressed form of the verb biti ('be') are found in the rubrics. The $3^{\text {rd }}$ person pl. is confirmed to end in final -tb, with the ending -utb having spread as a result of alignment with thematic verbs. The endings of the synthetic imperative plural tend to be aligned. Despite examples of reciprocal alignment in the Proprium de tempore of the Second Beram Breviary, alignment of e-type verbs according to endings with the formant $i$ is more common than vice versa. It is also characterised by the prevalence of the morpheme $-m o$ in the $1^{\text {st }}$ person pl., with mostly older morphemes in the present, and $3^{\text {rd }}$ person sg. forms also being confirmed.

All three types of the aorist are found in the text analysed. In the two sygmatic forms of the aorist, among innovative linguistic features, is the ending -smo in the $1^{\text {st }}$ person pl., although the older ending -homb/-hom'/-hom has mostly been preserved, as confirmed in other Croatian Church Slavonic liturgical texts, while in the $1^{\text {st }}$ person dual of the sygmatic first aorist the ending -sve is found. Both endings represent innovations resulting from paradigmatic alignment with the $2^{\text {nd }}$ person sg. (-ste) and the $2^{\text {nd }}$ and $3^{\text {rd }}$ person dual (-sta).

The imperfect is mostly characterised by contracted verb stem forms, although many uncontracted forms are also found. An innovation is the coexistence of grammatical morphemes -hota and -šeta in the $3^{\text {rd }}$ person dual, with the newer ending -hota, based on the $1^{\text {st }}$ person dual -hove being more prevalent. In one example of the $1^{\text {st }}$ person pl. the ending -homo is found, while in the $2^{\text {nd }}$ person $\mathrm{pl}$. the newer, analogical ending -hote is more common.

Key words: The Second Beram Breviary, Proprium de tempore, present, synthetic imperative, imperfect, aorist

Sanja ZUBČIĆ

Faculty of Humanities and Social Sciences

Rijeka (Croatia)

sanja.zubcic@uniri.hr 
